\title{
Nictitating Membrane
}

National Cancer Institute

\section{Source}

National Cancer Institute. Nictitating Membrane. NCI Thesaurus. Code C77657.

A translucent membrane present in the eye of some animals, also called the third eye. It

is part of the conjunctiva and protects the eye from debris and dry air. 